\title{
POLYLACTIC ACID AND ITS COMPOSITES: SYNTHESIS AND ADVANCEMENTS
}

\author{
Shubhra Jain, Zubin Roy, Shikha Singh, Sumit Sharma and Saurabh Jyoti Sarma*
}

Department of Biotechnology, School of Engineering and Applied Sciences, Bennett University, Greater Noida, Uttar Pradesh, India.

\begin{abstract}
The bio-based polymer Poly-Lactic Acid (PLA) exists as one of the commercialized, environmentally sustainable, and bio-degradable products. Due to its inherent properties, it is currently being implemented in a variety of polymer-dependent industries such as automotive, electronics, packaging, 3D printing, etc. The knowledge of these properties and the process of production for such PLA-based bioplastics, in conjunction with modifications to said processes for appropriate application in specific areas, have catapulted scientific, technological, and commercial advances in this field. In this review, synthetic and bio-based lactic acid production process, recovery and polymerization into PLA, and various applications such as in tissue engineering and drug deliveries have been summarized. The major interest is given to PLA-based composites and their utilization. It provides an in-depth assessment of the various methods and techniques implemented for PLA production and use.
\end{abstract}

\section{Keywords}

Lactic acid; Fermentation; Polymerization; Polylactic acid; Polylactic acid composites.

\section{ABBREVIATIONS}

PLA: Poly Lactic acid; LA: Lactic acid; L-LA: L-lactic acid; D-LA: D-lactic acid;

LAB: Lactic acid Bacteria; D-LDH: D-lactic Acid Dehydrogenase; L-DHA: L-Lactic Acid Dehydrogenase; MPEG-PLA: Monomethoxy poly (ethylene glycol)-poly (lactic acid),

ND-ODA PLLA: Octadecylamine-functionalized Nanodiamond (ND-ODA) poly (L-lactic acid): PGA: Polyglycolic acid; PEG: Polyethylene Glycol; NP: Nanoparticle; PDLLA: Poly-D-L-lactic acid; PDLA: Poly D-lactic acid

\section{Introduction}

Pollution is caused by the discharge of harmful pollutants in the natural environment . Among those pollutants, plastic is highly detrimental to not only the environment but to wildlife and human beings also. Plastics can be said to be originated in 1907, with the invention of Bakelite. This 'Material of a Thousand uses' brought about the rapid production of plastics, which resulted in 7.8 billion tonnes of plastics accounted for by the year 2015. This type of plastic is derived from the conventional petrochemical process that harms the environment and ecology in several ways such as the digestive toxicity to the organisms, use of toxic chemicals during production. This also leads to the upsetting of the food chain and climatic conditions due to the discharge of toxic gases upon combustion . The potential solution of plastic management is the accumulation of plastics in landfills. However, this causes land pollution, and its subsequent interaction with water forms toxic chemicals which then seep into groundwater causing its pollution . Estimations suggest that each year, up to 2.41 million tonnes of plastic enters the oceans .

Polylactic acid or poly-lactide is an environmentally sustainable, compostable, and biodegradable, biopolymer obtained from renewable resources. In 1932, Carothers proposed a lactic acid-derived aliphatic polyester. Among bio-based polymers, it is the most widely studied, utilized, renewably sourced aliphatic biopolymer. It provides an alternative to fossil fuel-based plastics and reduces the negative impact on the environment which results from the accretion of such non-degradable plastics. Polylactic acid (PLA) is obtained from the monomer lactic acid (LA) also 
known as '2-hydroxy propanoic acid'. PLA is one of the renewably sourced commodity polymers that is implemented to replace the currently using plastic material. United States Food and Drug Administration (FDA) identifies PLA in the category of generally recognized as safe (GRAS) , in addition to approving it to be in direct contact with biological fluids. Even among biopolymers, using PLA provides additional advantages such as the fact that its production utilizes carbon dioxide and better processability using fiber spinning, injection molding, etc. The life cycle of PLA is explained in Figure 1. Another strength attributed to PLA is its biocompatibility since PLA itself is not toxic or non-carcinogenic and neither are its degradation products which makes it an appealing choice for biomedical applications. Its biocompatibility can be attributed to the fact that PLA hydrolyses into $\alpha$-hydroxy acid after implantation into the human body, gets assimilated into the citric acid cycle . It also has good physio-mechanical characteristics such as high tensile and elastic strength. Usage of PLA has been limited from the complete replacement of oil-based plastics due to drawbacks like flame retardancy, brittle nature, poor thermal and mechanical properties at higher temperatures, slow rate of degradation, etc. However, the production of tailor-based products or the use of PLA in conjunction with co-polymers specifically targets such limitations.

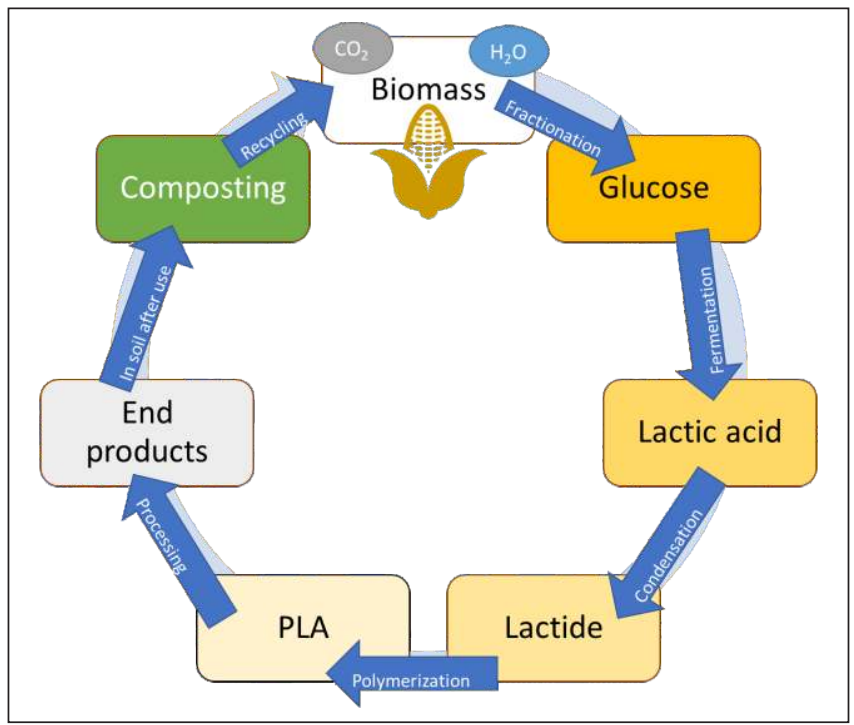

Figure 1: General life cycle of PLA showing stages of production and degradation.

\section{PLA APPLICATIONS FOR COMMERCIAL USE AND MARKET}

The drawbacks of oil-based plastics made it imperative to replace them and led to the inception of bioplastics. Due to an ever-increasing demand for plastics, immense social and scientific endeavors were taken to come with various biopolymers. According to the European Bioplastics market, 2.11 million tonnes of bioplastic were globally produced as of 2019 and in 2024, it is estimated to reach 2.43 million tonnes -(12). Among those biopolymers, PLA quickly became the most widely studied and utilized biopolymer due to the many exceptional advantages it has over other biopolymers such as the raw materials required being renewable, having lower energy consumption for production and transformation along with better processability, and a lower amount of toxic fumes being released upon incineration, etc (13). PLA had a worldwide global market value of 689 million USD and is estimated to reach 2.09 Billion USD by 2023 (14). Unique traits like its biocompatibility, thermoplastic processability, biodegradability, etc. coupled with the ability to alter its properties through modifications to suit specific needs have allowed for PLA to be employed in a variety of applications. The most commonly utilized biodegradable polymers employed in the biomedical include poly $\alpha$-hydroxy acids like Polydioxanone, Polyglycolic acid, PLA, etc (15). PLA has been implemented in the manufacturing of various biomedical equipment like bioabsorbable implants, sutures, tissue engineering scaffolds, covering membranes, delivery system materials, etc.

\section{Tissue Engineering}

It is the biomedical engineering field focusing on the development of substitutes for the maintenance, restoration, and improvement of tissues. The major advantages of this field include no requirement of a donor and a lack of transplant rejection (16). Metals as materials for use in tissue engineering had good mechanical properties but did not possess any biodegradability (17). Biostable materials such as PLA were initially utilized as scaffolds for the culturing of cells, which were then transplanted into the tissue. However, in recent times, such materials are developed as supports since they dissolve or degrade from the site of transplantation, resulting in an unimpaired patch of natural tissue (18). PLLA fibers have been proposed for tendon and ligament reconstruction and for a stent in urological and vascular surgery since these applications require a long retention time of strength (19). A three-dimensional PLA porous scaffold has been manufactured for the culturing of various types of cells, for use in cardiovascular disease treatment through cell-based gene therapy, and other orthopedic or neurological ailments _ (2022). Zhang et al. (2011) produced an ND-ODA/PLLA composite similar to the human cortical bone as also an improved alternative for drug delivery through surface modifications (23). BioSeed ${ }^{\circledR}-\mathrm{C}$ made from Vicryl (PLA/PGA), is one of the examples of clinically used biopolymer scaffolds and is utilized in cartilage repair (24). Shim et al. (2010) presented a 3Delectrospun scaffold as a favorable cell infiltration and bone formation substrate utilizing a rabbit calvarium defect model and highlighting its use in tissue engineering (25). Ritz et al. (2017) presented 3D-printed discs and cages composed of PLA and filled or coated with collagen promoting cell growth, proliferation, and induction of neo-vessel formation (26). Presently, 3D printing has found its niche application in tissue engineering due to its ability to provide patient-specific biomedical devices using anatomical data (27). Several 3D printed - PLA-based composite scaffolds with improved biocompatibility have been developed for bone repair (2831). 


\section{Drug delivery systems}

Pharmaceutical companies are constantly trying to innovate and improve the targeted delivery of drugs, maximizing their therapeutic effect and minimizing any side effects. PLA features allow it to be used in the manufacturing of microparticles (MP), nanoparticles (NP), pellets, microcapsules, etc. It was observed that properties like drug loading, release profiles, particle size, etc. could be controlled through ranging ratios of blends MPEG-PLA (32). PLA has been implemented as microspheres in facial reconstructive surgery and transcatheter arterial embolization (33, 34). Electrospun nanofibers PLA/poly (butylene adipate) blend was developed for the regulated release of teriflunomide, an antirheumatoid agent (35). PLA-PEG NP was presented as nasal protein carriers via nasal administration(36). PLA vesicles have been manufactured in the form of insulin carriers via oral administration (37). A copolymer of PLA and ethylene-vinyl acetate have been produced as drug carriers, where the amount of PLA regulated the amount of drug released (38). PLA-based commercial products are also available in the dermatological field with Sculptra ${ }^{\circledR}$ as a dermal filter for non-surgical facial rejuvenation(39).

\section{Medical implants}

PLA is also implemented in implants such as pins, plates, wires, screws, etc. PLA has been successfully used to manufacture screws and plates for the treatment of fractures (40). Ocular implants were created using PLA and polyvinyl pyrrolidone (PVP) blends (41). Blends of PLLA/PDLLA and their potential in orthopedic or dental implants have also been studied (42). 3D printing was utilized to create an economical PLA/hydroxyapatite screw implant to make it more feas ible for clinics, who could print the implant themselves(43).

\section{Other commercial applications}

Due to the similar properties of PLA to commercially available plastics, it is a good environmentally friendly alternative for packaging applications. The economic feasibility of PLA as such an alternative has been highlighted in a detailed manner by Fahim et al. (2019). It has been concluded that by replacing all synthetic plastic products with PLA-based products, the global GHG emissions can be reduced by 800 million tons (44). NatureWorks LLC is at the forefront of the PLA production market and its Ingeo ${ }^{\mathrm{TM}}$ is implemented in a variety of applications such as 3D printing, cosmetics, household products, construction, packaging, electronics, and appliances, etc $(45,46)$. Kasirajan et al. (2019) created a PLA/Chitosan-based composite bioplastic using Prosopis juliflora, which is an invasive weed in agricultural fields in Asia (47). PLA is also applied in active antimicrobial packaging for application in food packaging, through incorporation or coating with antimicrobial agents (48). Futerro which is a subsidiary of Galactic, a leading Belgian Biotechnology Company, produces PLA fibers for packaging applications $(49,50)$. Corbion NV, the parent company of PURAC, produces a range of products like standard, high heat, low heat PLA, and PDLA for use as nucleating agents, under the name of Luminy ${ }^{\circledR}$, in partnership with the Total S.A. It also produces PLA-based components such as air filters, interior trim parts, etc. under the name of Plantura ${ }^{\mathrm{TM}}$, along with Röchling Automotive. It also partners with Synbra and SULZER to produce PLA- based Bio foams (5154). Arjmandi et al. (2017) highlight recent developments in PLA nanocomposites for their application in the automotive industry (55). Kenaf fibrereinforced PLA is used in spare tire covers and is also utilized in mobile phone shells (56). The above-mentioned instances are few examples of the wide-ranging nature of the applicability of PLA and its potential as an alternative to synthetic plastics.

\section{Lactic acid synthesis}

The synthesis of lactic acid (LA) generally takes place chemically or by microbial fermentation. In the case of purity, chemically produced lactic acid has less purity due to the formation of racemic mixtures while through microbial production, the pure form could be obtained. L- and D- forms of LA, are the two enantiomers. L-Lactic acid is optical pure in comparison to D-LA and is utilized for producing high crystalline polylactic acids having high melting temperatures (57). The manufacturing process of PLA includes the fermentation of lactic acid in the presence of suitable microorganisms. The overall manufacturing process of PLA is shown in Figure 2. The lactic acid is recovered from the fermentation broth using separation techniques such as 2-D electrodialysis or membrane filtration. After purification and recovery, the monomer of lactic acid is changed to a polymer state by polymerization.

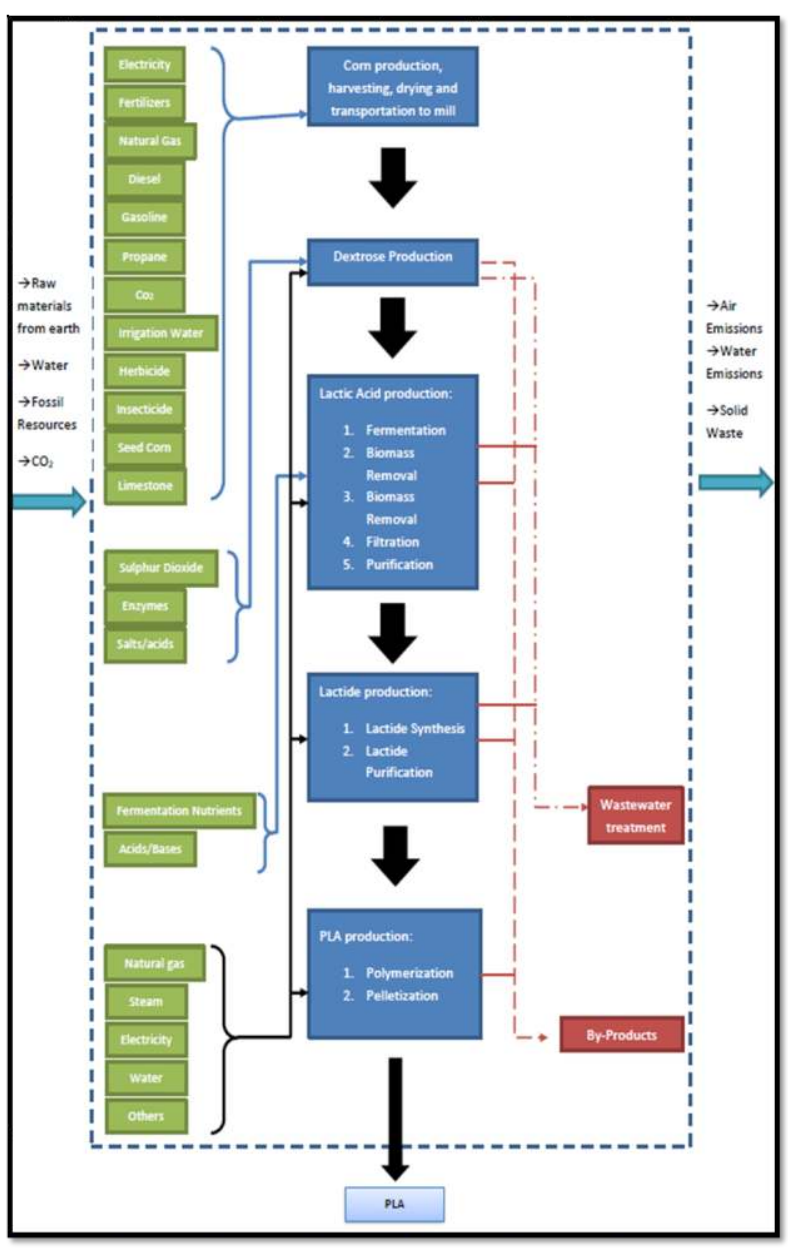

Figure 2: Clarified depiction of PLA manufacturing with the inclusion of a wastewater treatment plant inside the system boundary. The inputs are shown on the right side whereas the emissions at the left 


\section{Chemical synthesis of lactic acid}

The lactonitrile route is proposed as the conventional route for LA production. The first step involves the addition of hydrogen cyanide to acetaldehyde under high pressure and the presence of a base that results in the formation of Lactonitrile. Further Lactonitrile is recovered from the crude and purified by distillation. Lactic acid is formed when Lactonitrile is hydrolyzed in the presence of strong acids such as $\mathrm{HCl}$ and $\mathrm{H}_{2} \mathrm{SO}_{4}$. Methyl lactate is formed via lactic acid esterification in the presence of methanol. Then, it is further hydrolyzed via water when the acid catalyst is present, to form lactic acid, along with methanol as an end product (57). Monsanto, Texas, USA was the initial manufacturer of LA by chemical synthesis in 1963. The method is expensive and requires several by-products that are obtained from fossil fuel-based industries. Another limitation is the formation of the racemic mixture(58).

\section{Biological synthesis of lactic acid}

Industrially, LA is mainly produced by bacterial fermentation because of the advantages such as the use of low production cost compared to chemical synthesis, renewable sources are used as substrates, and produces optically pure isomers of LA. The process involves the breakdown of sugars by microorganisms into products like ethanol, lactic acid, and citric acid. The use of pure substrates yields optically pure products but thereby increases the production cost (58). Different substrates have been studied for LA production as mentioned in Table 1.

Table 1: Renewable sources used for the production of Lactic acid.

\begin{tabular}{|l|l|c|c|}
\hline Substrate & Method & Yield & Refs \\
\hline Cassava & Simultaneous saccharification and co-fermentation & 112.5 g L-1 & $(59)$ \\
\hline Sugarcane bagasse & Simple fermentation & 55.99 g L-1 & $(60)$ \\
\hline Agro-industrial waste & Batch fermentation & 89.4 g L-1 & $(61)$ \\
\hline Cheese whey & Hydrolysis and fermentation & 51.2 g L-1 & $(62)$ \\
\hline
\end{tabular}

Based on the bacteria used the process is classified into two broad categories: Homo-fermentative and Heterofermentative method. Due to its higher product yield and low by-product formation, the homo-fermentative method is generally used in industries. L.bulgaricus, L. amylophilus, L. delbrueckii are some of the Lactobacillus species at a temperature range of $38-42{ }^{\circ} \mathrm{C}$, $\mathrm{pH}$ ranges between 5.4-6.4 and the concentration of oxygen is kept low. Theoretically, 1.8 moles of LA are produced from 1 mole of hexose, which is around $90 \mathrm{~g}$ of LA is produced from $100 \mathrm{~g}$ of glucose. Byproducts are formed at low levels (63). The heterofermentative method is characterized by the production of ethanol, mannitol, glycerol, carbon dioxide, and acetic acid, as by-products. The phosphoketolase pathway or 6 phosphogluconate pathway is used by the obligatory heterofermentative lactic acid bacteria (LAB), while both the pathways are used for the production of LA by facultative heterofermentative mode (58). LAB requires a complex nutrient supply as its ability to synthesize Vitamin B and amino acids is very low. Simple sugars such as maltose, glucose are used to feed the bacteria. Depending on the operating conditions, LAB may produce both isomers in small quantities, but generally, only one type of isomer is produced by LAB. Fermentation efficiency is affected by parameters such as temperature, $\mathrm{pH}$, vitamin, nitrogen source, substrate, and choice of micro-organisms being the most important parameter. Filamentous fungi such as Rhizopus are also used for the production of LA. Rhizopus can utilize glucose for conversion into LA in an aerobic system. The presence of amylolytic enzymes in Rhizopus species allows the conversion of starch into L-LA. Vigorous aeration is needed while producing LA as Rhizopus is an obligate aerobe. In comparison to LAB, the rate of production is low (58). The co-culture technique was also studied for productivity. In a study, it was seen that when genetically engineered Enterococcus faecalis N4 was co-cultured with L. pentosus, productivity obtained $3.68 \mathrm{~g} \mathrm{~L}^{-1} \mathrm{~h}^{-1}$ after 12 hours of fermentation, proving that a combination of both may increase the productivity(58).

\section{STRATEGIES APPLIED FOR LACTIC ACID ADVANCEMENTS}

Metabolic engineering for lactic acid microbes

This advanced technology is used to design strains that can result in higher production of LA at low cost thereby reducing or removing the by-product formation. The basic problem of LA strains which led to the use and optimization of this technique is the utilization of limited substrates and low acid tolerance. In 2016, a study was done on the D-ldh gene, transferred from Leuconostoc mesenteroides into S. cerevisiae (63). CRISPR Cas9 system was used to metabolically engineer Schizosaccharomyces pombe strain, to produce D-lactic acid from cellobiose and glucose. ADH, GDP, and PDH genes were removed and gene encoding for D-ldh in Lactobacillus plantarum was introduced into the genome of fission yeast. Results showed that $35.5 \mathrm{~g} \mathrm{~L}^{-1}$ of glucose was consumed with a yield of $0.71 \mathrm{~g}$ D-LA/g of glucose (64). D-LDHA gene from Leuconostoc mesenteroides was expressed in S. cerevisiae strain JHY5610, whereas the genes involved in the production of the by-products such as glycerol and ethanol were deleted. A new strain named S. cerevisiae JHY5710 was formed as a result of adaptive laboratory evolution. PDCI gene was deleted from the strain JHY5710 and the L-DHA gene from Leuconostoc mesenteroides was added to the strain which was further labeled as S. cerevisiae JHY5730. The production yield of DLA was found to be $0.83 \mathrm{~g} / \mathrm{g}$ of glucose(65). 


\section{Immobilization of cells}

The emerging demand for lactic acid globally results in the requirement of new techniques aiming a higher yield production is needed. Immobilization reduces the waste of biocatalyst activity thereby providing an advantage of reusing it. During, LA production it is important to produce higher yields to fill in the global demand thereby keeping the manufacturing cost low leading to the designing of metabolically engineered biocatalysts. These biocatalysts are expensive and hence the loss of their activity is a threat during production which leads us to think about how to recycle these biocatalysts. Hence, immobilization appeared as a new technique that can allow the reuse of these biocatalysts thereby maintaining a low cost. The basic principle behind the technique is to fix the biocatalyst at specific regions, physically or chemically for a specified reaction to being carried out. Productivity in this case is dependent on the immobilization method and the supporting material used (58). Calcium alginate is one of the most commonly used immobilization matrixes. The method is not used industrially for the production of LA due to the chances of reaction between citrate and phosphate ion which may hamper the process thereby disrupting the immobilized cells leaving the cells free in the fermenter reactor (66). Hence, the need for a new catalyst led to the formation of a mesoporous silicabased material, on which the living cells of Lactobacillus rhamnoses were immobilized. This showed higher efficiency experimentally as no dissolution of the matrix took place. In a study conducted in 2016, Rhizopus oryzae was immobilized on a fibrous matrix in a stirred bioreactor with cell-free fermentation broth. The fermenter design along with other maintained environmental conditions favored the immobilization and high production yield of lactic acid without substrate limitation (67). Immobilized Lactobacillus casei was used for L-lactic acid production from molasses as a substrate along with corn steep liquor as a nitrogen source. Several matrixes such as chitosan, PVA-alginate, sodium alginate, and others were tested. Double layer coated alginate beads immobilized with chitosan and Lactobacillus casei had high stability as well as entrapping efficiency

(68).

\section{Fermentation with cell recycling}

Cell recycling systems improve process productivity by supporting production at high cell density. The insertion of the microfiltration membrane gives uniqueness to the system. Firstly, the basic systems and stirred tank reactors are joined, whereas, after completion of production, the medium reaches the cross-flow microfiltration module after transfer from the bioreactor (58). In a study, xylose was converted to L-lactic acid by using this method where $0.789 \mathrm{~g} \mathrm{~g}^{-1}$ of yield was obtained with $32.3 \mathrm{~g} \mathrm{~L}^{-1}$ concentration (4). Via the hollow fiber membrane cell recycles fermentation system, recombinant E.coli was used for D-lactic acid continuous production where gene activating pyruvate formate-lyase enzyme was deleted and heterologous $\beta$-glucosidase was expressed on the cell surface. The process was carried out in a jar fermenter under anaerobic conditions using cell recycle fermentation. 4.3-5.0 $\mathrm{g} \mathrm{L}^{-1}$ of D-LA was produced from cellobiose directly for continuous production - (69).

\section{Concurrent fermentation and saccharification}

Concurrent fermentation and saccharification have been recently investigated and involves microbial fermentation and one-step enzymatic hydrolysis. LA was produced using sugar bagasse as the substrate using this method. The average productivity was obtained of $0.78 \mathrm{~g} \mathrm{~L}^{-1} \mathrm{~h}^{-1}$ while $1.14 \mathrm{~g} \mathrm{~L}^{-1} \mathrm{~h}^{-1}$ was observed when sugar concentration was increased by solubilizing bagasse (70). The use of this process reduces the time of processing thereby decreasing the inhibition of glucose.

\section{Lactic acid recovery}

Fermented broth obtained post-fermentation contains LA with several impurities such as sugars, amino acids, proteins, and inorganic salts. To obtain the pure polymer, separation, and recovery from the fermentation broth are important. Solvent extraction, reactive distillation, membrane filtration, hybrid short path evaporation, ion exchange resins are some of the methods studied for purification (71). The methods used for separation and recovery are compared in Table 2.

Membrane separation is widely studied as an alternative for LA purification. Nanofiltration, electrodialysis, ultrafiltration, and microfiltration are membrane-based

Table 2: Comparative study of different separation processes used for lactic acid recovery.

\begin{tabular}{|c|c|c|}
\hline Method & Advantages & Disadvantages \\
\hline Precipitation & $\begin{array}{l}\text { - } \quad \text { Simple process. } \\
\text { - } \quad \text { High yield. } \\
\text { The composition of fermentation broth } \\
\text { does not affect the yield. }\end{array}$ & $\begin{array}{l}\text { - } \quad \text { Several filtration steps are needed. } \\
\text { - } \quad \text { Expensive. }\end{array}$ \\
\hline $\begin{array}{l}\text { Liquid-liquid } \\
\text { extraction }\end{array}$ & $\begin{array}{l}\text { - } \quad \text { The risk of thermal degradation is reduced. } \\
\text { - } \quad \text { Chemicals used can be recycled. } \\
\text { - Energy consumption is less. }\end{array}$ & $\begin{array}{l}\text { - } \quad \text { Distillation needs to be done for recovery. } \\
\text { Chemicals used should have high } \\
\text { distribution coefficients are needed. }\end{array}$ \\
\hline Membrane process & $\begin{array}{l}\text { - The purification level is high. } \\
\text { - The rate of selectivity is high. } \\
\text { It can combine with conventional fermenters } \\
\text { thereby lowering equipment costs. } \\
\text { - Power consumption is low. }\end{array}$ & $\begin{array}{l}\text { - } \quad \text { The membrane may disrupt. } \\
\text { - } \quad \text { Scale-up is difficult. } \\
\text { Expensive. }\end{array}$ \\
\hline
\end{tabular}




\begin{tabular}{|l|l|l|}
\hline Reactive distillation & $\begin{array}{l}\text { Lower down cost. } \\
\text { Chemical recycling. } \\
\text { No requirement of catalyst. } \\
\text { The purification rate is high. }\end{array}$ & $\begin{array}{l}\text { Complex process. } \\
\text { The homogenous catalyst can get corroded } \\
\text { easily. } \\
\text { Used specifically in chemical reactions } \\
\text { performed reversibly in the liquid phase. }\end{array}$ \\
\hline
\end{tabular}

techniques used often. The semi-permeable membrane acts as a physical hurdle for the transfer of solutes, which are further divided into two distinct phases blocking the mixing of the components of the two phases. For the separation of organic acids, electrodialysis is considered one of the efficient approaches. Selectively permeable anionic and cationic membranes are alternatively arranged between cathode and anode. The ions disperse to the cathode and anode based on charge when electricity is applied. This process is used to concentrate the ions in a solution or remove salts. Membranes are non-porous and have a diameter of 10$500 \mu \mathrm{m}$. Monopolar and bipolar electrodialysis has been mainly used for LA separation .

A monopolar or conventional electrodialysis system is a twocomponent system having two sets of anionic and cationic exchange membranes. The system is used for demineralizing or concentrating organic acids. Due to its function of counter ion competition, the system can efficiently separate the organic acid mixture. The bipolar membrane electrodialysis system has gained interest in the past 10 years because of its low effect on the environment . Water dialysis helps to complete the fulfilment of $\mathrm{H}+$ required during the separation and hence no addition of inorganic acids is required. It also helps in the recovery of the base which is required for $\mathrm{pH}$ adjustment. An electrodialysis system was prepared using CMI7000 cation exchange membranes, to check the efficiency of separation of LA from fermented whey. Results showed that LA along with other organic acids was successfully separated using the above chose membranes . LLA was produced by hydrolyzing the organic fraction of municipal solid waste. Monopolar electrodialysis was used for the pre-treatment, where LA was concentrated, and D-LA was removed thereby leaving only L-LA after separation. The optical purity of the enantiomer was observed to be $98 \%$.

\section{PLA processing: from monomer to polymer}

\section{Direct condensation polymerization}

It is a difficult technique in the case of free solvent systems but is the cheapest route of polymer synthesis. PLA is then produced from high molecular weight LA is more abundant due to its high demand . Low molecular PLA is formed as a result of self-condensation where hydroxyl and carboxyl groups are present in equal concentrations. Various coupling agents are added to form high molecular weight PLA as they will react with the present hydroxyl or carboxyl groups thereby increasing the coupling rate. To acquire high thermal stability, PLA was produced from lactic acid by direct condensation polymerization in the presence of microperlite. Microperlite in the reaction increased the molecular weight of the resultant polymer and increased the rate of crystallinity.
It was observed that perlite blocks the rate of degradation due to temperature increase in crystallinity caused by improved orientation of the side chain. FTIR, GPC, and DSC in combination with XRD were used to analyze the chemical structure, molecular weight, and crystallinity, whereas DSC in combination with TGA was used to explore the thermal stability of the polymer. As a result, the temperature for degradation and crystallinity of the polymer was found to be increased which consequently increased the thermal stability of the polymer .

\section{Direct polycondensation in an azeotropic solution}

The polymer produced with direct polycondensation has problems such as low molecular weight and is of low quality due to the problems associated with the elimination of the byproducts. Several new methods have been developed to overcome this disadvantage where azeotropic and solid-state polymerization are the two main methods used . In azeotropic polymerization, azeotropic solvents are used for the elimination of water. In organic solvents, the equilibrium between monomers and polymers is controlled to produce high molecular weights. The impurities caused by depolymerization and racemization are kept away by lowering down the applied temperature than the polymer melting point.

In an experimental setup microwave system, PLA was synthesized by direct melt condensation polymerization. Microwave power and temperature were kept constant throughout the experiment by applying to cool externally, and for the Microwave transparent liquid, o-xylene was used. PLLA synthesis by L-lactide via ROP method and DMP method was studied to check for the properties of the products obtained and the energy efficiency of both the systems. It was concluded, that $73 \%$ of energy-saving was successfully achieved in MW-DMP whereas the production rate also increased by $37.7 \%$.

\section{Ring-opening polymerization}

Ring-opening polymerization (ROP) synthesizes functionalized polylactides and polylactides having high molecular weight. The formation of these polymers takes place when the cyclic monomers of ester react with a catalyst and a co-initiator. The initiator or the catalyst is responsible for initiating the reaction. Depending on the type of catalyst ROP is classified into three major reactions: anionic, cationic, and co-ordination insertion . Cyclic dimers of LA formed are referred to as polylactide. The process involves the removal of water from aqueous LA kept in continuous condensation to form prepolymers or oligomers. By transesterification, the obtained prepolymer is catalyzed to form a cyclic dimer which is further purified. The PLA formed is present in three 
forms- D, L, or Meso lactide, where the first two forms are optically active. At the industrial scale, the lactide's ROP leads to the formation of a family of Lactide co-polymers .

\section{PLA based composites}

To address the drawbacks of PLA, reinforcing fibers, MP, NP, and selective additives are added within the PLA matrix to achieve improvements in properties and specific characteristics. The different materials used for reinforcement of PLA are shown in Table 3.

\section{PLA reinforced with fibers}

\section{PLA-flax}

PLA-flax and PLA composites were manufactured via a film stacking technique, resulting in higher Young's modulus and tensile strength when differed to similar Polypropylene (PP)flax composites and quite similar to glass fiber polyester composites counterparts. Hence, it was concluded to be a good alternative for glass fiber reinforced unsaturated polyester resins. Sheets produced from both standard and modified PLA-flax mat composites had improved stiffness and impact resistance for PLA . It has been observed that flax fiber content is a vital element in the determination of physical and mechanical characteristics of the composite and increasing flax fiber content results in improved mechanical properties. PLA-flax is a promising material for the automotive industry and can be used as an alternative to PPflax composites which are utilized currently in several automotive panels. Modified PLA-flax composites with improved toughness and matrix-fiber interactions were obtained through the treatment of Flax fiber surface with corona discharge, aminopropyltriethoxysilane treatment, alkali treatment, and maleic anhydride (MA) grafting.

\section{PLA-kenaf}

Kenaf fiber was found to be a good reinforcement fiber for high-performance biopolymers after observing the improvements in properties in PLLA-kenaf composite as compared to kenaf and PLA sheets by themselves . Lee et al. (2009) produced a PLA-kenaf composite with improved mechanical properties, higher heat deflection temperatures (HDT), and reduced water swelling than the standard PLA polymer. Even low (1-5\%) Kenaf loadings displayed good matrix-fiber adhesion and improved mechanical properties in PLLA-kenaf composites .

\section{PLA fibers: glass, carbon}

RTP Company is a manufacturer of custom thermoplastic compounds and produces PLA-GF compounds with improved mechanical properties such as higher stiffness, tensile strength, flexibility, and HDT . Wang et al. (2019) used silane-modified GF (m-GF) for reinforcement of PLA which achieved greater rigidity, strength, and toughness, and was concluded to be a good candidate for use in automotive and aircraft industries. Ferreira et al. (2017) highlighted the difference in characteristics of PLA-CF and PLA concerning $3 \mathrm{D}$ printing. It was reported that short carbon fibers resulted in an increment of the tensile strength of about 2.2 times in the case of PLA-CF composites, as compared to the neat PLA. Li et al. (2016) created a modified CF reinforced PLA composite through a 3D printing approach known as rapid prototyping. It had $13.8 \%$ and $164 \%$ higher tensile and flexural strength respectively when compared to original PLA-CF composites. PLA-CF composite with enhanced toughness, interfacial capabilities, and good electrical properties was made using styrene-ethylene-butylene-styrene block grafted with maleic anhydride copolymer .

\section{PLA-cellulose}

PLA-cellulose nanocomposites resulted in higher storage modulus and yield strength. PLA-Lyocell composite achieved higher tensile strength, the greater value of Young's modulus and hardness, when compared to similar PP and PPbased composites . PLA-Cellulose sphere obtained through the Emulsion-Solvent Evaporation Method was compressed and molded to achieve a biocomposite film. The films had improved toughness, elongation at break, and strength.

\section{PLA-Wood}

PLA-wood composite strengths improve due to the wood's inherent strength . Some commercially available PLA-wood composites are Timberfill by Filamentum (70\% PLA-30\% Wood), corkFill/woodFill by ColorFabb, EasyWood by FormFutra etc .

\section{PLA composites with fillers}

Talc

One of the most commonly utilized fillers due to its ability to improve PLA performance at varying loadings. It improves heat resistance, stiffness, molding capacity and reduces production costs for PLA-based composites. The addition of $2 \%$ talc resulted in a 65-fold reduction in Isothermal

Table 3: Materials utilized for PLA reinforcement (82).

\begin{tabular}{|l|l|}
\hline PLA reinforcement & Type \\
\hline Fiber-reinforced PLA & Flax \\
\cline { 2 - 2 } & Kenaf \\
\cline { 2 - 2 } & Carbon and glass \\
\cline { 2 - 2 } & Cellulose \\
\cline { 2 - 2 } & Wood \\
\hline \multirow{5}{*}{ Filler reinforced PLA } & Talc \\
\cline { 2 - 2 } & Carbonaceous fillers \\
\cline { 2 - 2 } & Hydroxyapatite \\
\cline { 2 - 2 } & Barium Sulphate \\
\cline { 2 - 2 } & Calcium Carbonate \\
\hline
\end{tabular}

crystallization halftimes, which helps achieve higher crystallinity (an essential parameter for determining heat resistance) and faster processing $(101,102)$. It was concluded to be effective as an agent of nucleation for the enhancement of the rate of crystallization(102).

\section{Carbon filler}


Carbon fillers are utilized for improving PLA properties like mechanical, nucleating, electrical, etc. PLA-Carbon black composites with higher electromagnetic shielding effectiveness were obtained for use in the electronics industry (103). The conductivity and flexibility of PLA-based composites have also been enhanced using such fillers (104). PL-graphite also provided enhanced mechanical and electrical properties for application in the electrical and aerospace industries(105).

\section{Hydroxyapatite}

Hydroxyapatite is a preferred candidate for creating PLA composites to be used in the biomedical field due to its bonebonding capabilities, biocompatibility, and osteoconductivity. PLA-hydroxyapatite composites achieved enhanced bending strength and interfacial adhesion (106). Mechanical properties such as the tensile strength of PLA- hydroxyapatite were further improved using surfacemodified hydroxyapatite(107).

\section{Barium Sulphate}

Radiopaque pancreatic stents were created using PLABarium Sulphate $\left(\mathrm{BaSO}_{4}\right)$ (108). $\mathrm{BaSO}_{4}$ was also used for reinforcing PLA-based composites and increased the toughness, with the elastic modulus increasing along with increasing amounts of $\mathrm{BaSO}_{4}(109)$.

\section{Calcium carbonate}

PDLLA and Calcium carbonate were utilized in PLA composite production for utilization in biomedical applications such as bone replacements (110). Cranial reconstruction implants were made using $\mathrm{PLA}-\mathrm{CaCO}_{3}$ with enhanced bioactivity and biocompatibility (111).

\section{CURRENT PROSPECTIVE}

This study provides an overview of the various aspects of Poly-lactic acid such as production, improvements, and the application along with changes in trend at present. Though PLA has several advantages over conventional plastics and other biopolymers such as its biocompatibility, renewability, and increased processability, however, it also suffers from limitations such as its higher price compared to its counterparts, use of food crops which damages not only the availability of food but also deals in the destruction of natural habitats. It does not compost fast enough making it unsuitable for industrial composters and the compost itself does not improve the quality of soil, it has lower toughness and higher permeability leading to food spoilage in the case of its application on food packaging -(112). One solution currently implemented to deal with such limitations has been the ability to improve its properties according to the use, via blending different substances to create unique blends of PLA/PLAbased composites (113). Furthermore, it is one of the major reasons for the increased interest in its research. Further research and improvements need to be conducted on novel strains, higher yields, and innovative strategies to promote lower energy utilization without compromising the yield and quality of the PLA produced(114).
Up to the previous decade, PLA was majorly applied in packaging and biomedical applications. However, with newer emerging technologies such as 3D printing becoming mainstream, its range of implementations has further increased. Never avenues for the growth of lactic acid and PLA have emerged with an increment in its usage in cosmetic products like shampoos, creams, etc. due to its ability to lighten skin color, improving elastin and collagen synthesis, improving cell renewability, etc. Currently, 46\% of all PLA consumed is for its implementation in the packaging industry with countries like India, China, Russia, and Brazil holding $30 \%$ of the market share as global leaders in the PLA industry (115). Several governments and companies have now taken several steps and put in place new policies to reduce/restrict the use of petrochemical-based synthetic plastics and have allocated funds along with providing immense aid to researchers and R\&D departments for the development of inventive and innovative approaches to keep up with the everincreasing and necessary demand for its production. The provided in-depth assessment of the various methods and techniques, both traditional and emerging ones, that are implemented in the PLA production processes can be utilized in aiding further research and improvements shortly.

\section{ACKNOWLEDGEMENT}

The authors are grateful to Bennett University, Greater Noida for providing financial support to complete this work.

\section{CONFLICT OF INTEREST}

The authors do not have any conflict of interest.

\section{REFERENCES}

1. Pollution |National Geographic Society.

2. The Story of Bakelite, the First Synthetic Plastic.

3. Eriksen M, Lebreton LCM, Carson HS, Thiel M, Moore CJ, Borerro JC, Galgani F, Ryan PG, Reisser J (2014) Plastic Pollution in the World's Oceans: More than 5 Trillion Plastic Pieces Weighing over 250,000 Tons Afloat at Sea. PLoS One. https://doi.org/10.1371/journal.pone.0111913

3. Plastic bag bans can help reduce toxic fumes.

4. Causes, Effects and Incredible Solutions to Plastic Pollution You'll Wish You'd Known - Conserve Energy Future.

5. Lebreton L, Slat B, Ferrari F, et al. (2018) Evidence that the Great Pacific Garbage Patch is rapidly accumulating plastic. Sci Rep. https://doi.org/ 10.1038/s41598-018-22939-w

6. Plastic pollution | Sources \& Effects |Britannica.

7. Graefe G (1973) Holten, C. H.: Lactic Acid, Properties and Chemistry of Lactic Acid and Derivatives (Milchsäure, Eigenschaften und Chemie der Milchsäure und ihrer Derivate). With Contributions by A. Müller (Analytical Chemistry), D. Rehbinder (Biochemistry). Edited by St. Starch - Stärke 25:34-34.

8. Jamshidian M, Tehrany EA, Imran M, Jacquot M, Desobry S (2010) Poly-Lactic Acid: Production, 
applications, nanocomposites, and release studies. Compr Rev Food Sci Food Saf. 9:552-571.

9. Dorgan JR, Lehermeier HJ, Palade LI, Cicero J (2001) Polylactides: Properties and prospects of an environmentally benign plastic from renewable resources. Macromol Symp. 175:55-66.

10. Savioli Lopes M, Jardini AL, Maciel Filho R (2012) Poly (lactic acid) production for tissue engineering applications. In: Procedia Eng. Elsevier Ltd, or 1402-1413.

11. Market-European Bioplastics e.V.

12. Polylactic Acid or Polylactide, PLA Plastic, Lactic Acid Polymer Guide.

13. Polylactic acid market value globally 2023 | Statista.

14. Middleton JC, Tipton AJ (2000) Synthetic biodegradable polymers as orthopedic devices. Biomaterials. 21:2335-2346.

15. Langer R, Vacanti JP (1993) Tissue engineering. Science (80) 260:920-926.

16. Liu X, Ma PX (2004) Polymeric scaffolds for bone tissue engineering. Ann Biomed Eng. 32:477-486.

17. Gupta B, Revagade N, Hilborn J. (2007) Poly(lactic acid) fiber: An overview. Prog Polym Sci. 32:455-482.

18. Drselen $\mathbf{L}$, Dauner $\mathbf{M}$, Hierlemann $\mathbf{H}$, Planck $\mathbf{H}$, Claes LE, Ignatius A (2001) Resorbable polymer fibers for ligament augmentation. J Biomed Mater Res. 58:666-672.

19. Coutu DL, Yousefi A-M, Galipeau J. (2009) Threedimensional porous scaffolds at the crossroads of tissue engineering and cell-based gene therapy. J Cell Biochem. 108:537-546.

20. Kellomäki $\mathbf{M}$, Niiranen $\mathbf{H}$, Puumanen $\mathbf{K}$, Ashammakhi N, Waris T, Törmälä P (2000) Bioabsorbable scaffolds for guided bone regeneration and generation. Biomaterials 21:2495-2505.

21. Papenburg BJ, Liu J, Higuera GA, Barradas AMC, de Boer J, van Blitterswijk CA, Wessling $M$, Stamatialis D (2009) Development and analysis of multi-layer scaffolds for tissue engineering. Biomaterials. 30:6228-6239.

22. Zhang Q, Mochalin VN, Neitzel I, Knoke IY, Han J, Klug CA, Zhou JG, Lelkes PI, Gogotsi Y (2011) Fluorescent PLLA-nanodiamond composites for bone tissue engineering. Biomaterials. 32:87-94.

23. Ossendorf C, Kaps C, Kreuz PC, Burmester GR, Sittinger M, Erggelet C (2007) Treatment of posttraumatic and focal osteoarthritic cartilage defects of the knee with autologous polymer-based threedimensional chondrocyte grafts: 2-year clinical results. Arthritis Res Ther. https://doi.org/10.1186/ar2180.

24. Shim IK, Jung MR, Kim KH, Seol YJ, Park YJ, Park WH, Lee SJ (2010) Novel three-dimensional scaffolds of poly(L-lactic acid) microfibers using electrospinning and mechanical expansion: Fabrication and bone regeneration. J Biomed Mater Res Part B Appl Biomater.95B:150-160.

25. Ritz U, Gerke R, Götz H, Stein S, Rommens PM (2017) A New Bone Substitute Developed from 3DPrints of Polylactide (PLA) Loaded with Collagen I: An In Vitro Study. Int J Mol Sci. 18:2569.

26. Chia HN, Wu BM (2015) Recent advances in 3D printing of biomaterials. J Biol Eng. 9:4.

27. Yeon YK, Park HS, Lee JM, Lee JS, Lee YJ, Sultan MT, Seo Y Bin, Lee OJ, Kim SH, Park CH (2018) New concept of 3D printed bone clip (polylactic acid/hydroxyapatite/silk composite) for internal fixation of bone fractures. J Biomater Sci Polym Ed. 29:894-906

28. Zhang H, Mao X, Zhao D, Jiang W, Du Z, Li Q, Jiang C, Han D. (2017) Three dimensional printed polylactic acid-hydroxyapatite composite scaffolds for prefabricating vascularized tissue engineered bone: An in vivo bioreactor model. Sci Rep. 7:1-13.

29. Alam F, Shukla VR, Varadarajan KM, Kumar S (2020) Microarchitected 3D printed polylactic acid (PLA) nanocomposite scaffolds for biomedical applications. J Mech Behav Biomed Mater. 103:103576.

30.Zhang H, Mao X, Du Z, Jiang W, Han X, Zhao D, Han D, Li Q. (2016) Three dimensional printed macroporous polylactic acid/hydroxyapatite composite scaffolds for promoting bone formation in a criticalsize rat calvarial defect model. Sci Technol Adv Mater. 17:136-148.

31. Zheng XL, Kan B, Gou ML, et al. (2010) Preparation of MPEG-PLA nanoparticle for honokiol delivery in vitro. Int J Pharm. 386:262-267.

32. Imola MJ, Schramm VL (2002) Resorbable Internal Fixation in Pediatric Cranial Base Surgery. Laryngoscope 112:1897-1901.

33. Eppley BL, Morales L, Wood R, et al. (2004) Resorbable PLLA-PGA plate and screw fixation in pediatric craniofacial surgery: Clinical experience in 1883 patients. Plast Reconstr Surg. 114:850-856.

34. Siafaka PI, Barmbalexis P, Bikiaris DN (2016) Novel electrospun nanofibrous matrices prepared from poly(lactic acid)/poly(butylene adipate) blends for controlled release formulations of an anti-rheumatoid agent. Eur J Pharm Sci. 88:12-25.

35. Vila A, Sánchez A, Évora C, Soriano I, McCallion O, Alonso MJ (2005) PLA-PEG particles as nasal protein carriers: The influence of the particle size. Int J Pharm. 292:43-52.

36. Xiong XY, Li YP, Li ZL, Zhou CL, Tam KC, Liu ZY, Xie GX (2007). Vesicles from Pluronic/poly(lactic acid) block copolymers as new carriers for oral insulin delivery. J Control Release. 120:11-17.

37. Liu X, Lei L, Hou JW, Tang MF, Guo SR, Wang ZM, Chen KM (2011). Evaluation of two polymeric blends 
(EVA/PLA and EVA/PEG) as coating film materials for paclitaxel-eluting stent application. J Mater Sci Mater Med. 22:327-337.

38. Schierle CF, Casas LA (2011) Nonsurgical Rejuvenation of the Aging Face With Injectable PolyL-Lactic Acid for Restoration of Soft Tissue Volume. Aesthetic Surg J. 31:95-109.

39. Haers PE, Suuronen R, Lindqvist C, Sailer H (1998) Biodegradable polylactide plates and screws in orthognathic surgery: Technical note. J CranioMaxillo-Facial Surg. 26:87-91.

40. MORITA Y, SAINO H, TOJO K (1998) Polymer Blend Implant for Ocular Delivery of Fluorometholone. Biol Pharm Bull. 21:72-75.

41. Chen CC, Chueh JY, Tseng H, Huang HM, Lee SY (2003) Preparation and characterization of biodegradable PLA polymeric blends. Biomaterials. 24:1167-1173.

42. Liu A, Xue GH, Sun M, Shao HF, Ma CY, Gao Q, Gou ZR, Yan SG, Liu YM, He Y (2016) 3D Printing Surgical Implants at the clinic: A Experimental Study on Anterior Cruciate Ligament Reconstruction. Sci Rep. https://doi.org/10.1038/srep21704.

43. Fahim IS, Chbib H, Mahmoud HM (2019) The synthesis, production \& economic feasibility of manufacturing PLA from agricultural waste. Sustain Chem Pharm. 12:100142.

44. NatureWorks | Ingeo In Use.

45. https://core.ac.uk/download/pdf/56378549.pdf.

46. Kasirajan S, Umapathy D, Chandrasekar C, Aafrin V, Jenitapeter M, Udhyasooriyan L, Packirisamy ASB, Muthusamy S (2019) Preparation of poly(lactic acid) from Prosopis juliflora and incorporation of chitosan for packaging applications. J Biosci Bioeng. 128:323-331.

47. Tawakkal ISMA, Cran MJ, Miltz J, Bigger SW (2014) A review of poly(lactic acid)-based materials for antimicrobial packaging. J Food Sci. https://doi.org/10.1111/1750-3841.12534.

48. Futerro - Applications.

49. Galactic $>$ Home.

50. Biobased Polymers: Properties and Applications in Packaging - Pratima Bajpai - Google Books.

51. Corbion Purac at K 2013: partnering for PLA bioplastics growth - Plastics News, Plastics Product, Bags, Used Machines,plastics recycling,plastic Polymers, plastic news India.

52. Automotive|Total Corbion.

53. PLA(Poly Lactic Acid)|Total Corbion.

54. Arjmandi R, Hassan A, Zakaria Z (2017) Polylactic acid green nanocomposites for automotive applications. Green Energy Technol 193-208.
55. Graupner N, Herrmann AS, Müssig J (2009) Natural and man-made cellulose fibre-reinforced poly(lactic acid) (PLA) composites: An overview about mechanical characteristics and application areas. Compos Part AAppl Sci Manuf. 40:810-821.

56 Ghaffar T, Irshad M, Anwar Z, Aqil T, Zulifqar Z, Tariq A, Kamran M, Ehsan N, Mehmood S (2014) Recent trends in lactic acid biotechnology: A brief review on production to purification. J Radiat Res Appl Sci. 7:222-229.

57 Lactic Acid Production to Purification: A Review | Komesu|BioResources.

48 Chen H, Chen B, Su Z, Wang K, Wang B, Wang Y, Si Z, Wu Y, Cai D, Qin P (2020) Efficient lactic acid production from cassava bagasse by mixed culture of Bacillus coagulans and lactobacillus rhamnosus using stepwise $\mathrm{pH}$ controlled simultaneous saccharification and co-fermentation. Ind Crops Prod. 146:112175.

59. Alves de Oliveira R, Schneider R, Vaz Rossell CE, Maciel Filho R, Venus J (2019) Polymer grade L-lactic acid production from sugarcane bagasse hemicellulosic hydrolysate using Bacillus coagulans. Bioresour Technol Reports. 6:26-31.

60. Mladenović D, Pejin J, Kocić-Tanackov S, DjukićVuković A, Mojović L (2019) Enhanced Lactic Acid Production by Adaptive Evolution of Lactobacillus paracasei on Agro-industrial Substrate. Appl Biochem Biotechnol 187:753-769.

61. Juodeikiene G, Zadeike D, Bartkiene E, Klupsaite D (2016) Application of acid tolerant Pedioccocus strains for increasing the sustainability of lactic acid production from cheese whey. LWT - Food Sci Technol. 72:399-406.

62. Eş I, Mousavi Khaneghah A, Barba FJ, Saraiva JA, Sant'Ana AS, Hashemi SMB (2018) Recent advancements in lactic acid production - a review. Food Res Int 107:763-770.

63. Ozaki A, Konishi R, Otomo C, Kishida M, Takayama S, Matsumoto T, Tanaka T, Kondo A (2017) Metabolic engineering of Schizosaccharomyces pombe via CRISPR-Cas9 genome editing for lactic acid production from glucose and cellobiose. Metab Eng Commun. 5:60-67.

64. Baek S, Kwon EY, Bae S, Cho B, Kim S, Hahn J (2017) Improvement of $<\mathrm{scp}>\mathrm{d}</ \mathrm{scp}>$-Lactic Acid Production in Saccharomyces cerevisiae Under Acidic Conditions by Evolutionary and Rational Metabolic Engineering. Biotechnol J. 12:1700015.

65. Zhao Z, Xie X, Wang Z, Tao Y, Niu X, Huang X, Liu L, Li Z (2016). Immobilization of Lactobacillus rhamnosus in mesoporous silica-based material: An efficiency continuous cell-recycle fermentation system for lactic acid production. J Biosci Bioeng. 121:645-651.

66. Pimtong V, Ounaeb S, Thitiprasert S, Tolieng V, Sooksai S, Boonsombat R, Tanasupawat S, 
Assabumrungrat S, Thongchul N. (2017). Enhanced effectiveness of Rhizopus oryzae by immobilization in a static bed fermentor for L-lactic acid production. Process Biochem. 52:44-52.

67. Thakur A, Panesar PS, Saini MS (2019) l(+)-Lactic Acid Production by Immobilized Lactobacillus casei Using Low Cost Agro-Industrial Waste as Carbon and Nitrogen Sources. Waste and Biomass Valorization. 10:1119-1129.

68. Aso Y, Tsubaki M, Dang Long BH, Murakami R, Nagata K, Okano H, Phuong Dung NT, Ohara H (2019) Continuous production of D-lactic acid from cellobiose in cell recycle fermentation using $\beta$ glucosidase-displaying Escherichia coli. J Biosci Bioeng. 127:441-446.

69. Van Der Pol E, Springer J, Vriesendorp B, Weusthuis R, Eggink G. Precultivation of Bacillus coagulans DSM2314 in the presence of furfural decreases inhibitory effects of lignocellulosic byproducts during $\mathrm{L}(+)$-lactic acid fermentation. https://doi.org/10.1007/s00253-016-7725-z

70. Msuya N, Jhy K, Massanja E, Ak T (2017) Poly(lactic-acid) Production - from Monomer to Polymer: A Review.

71. Komesu A, Wolf Maciel MR, Rocha de Oliveira JA, da Silva Martins LH, Maciel Filho R (2017). Purification of Lactic Acid Produced by Fermentation: Focus on Non-traditional Distillation Processes. Sep Purif Rev. 46:241-254.

72. Separation and Purification Technologies for Lactic Acid-ABrief Review |Komesu|BioResources.

73. Alves De Oliveira R, Alexandri M, Komesu A, Venus J, Vaz Rossell CE, Maciel Filho R (2020) Current Advances in Separation and Purification of SecondGeneration Lactic Acid. Sep Purif Rev. 49:159-175.

74. Lech M, Trusek A (2018) Batch Electrodialysis of Lactic Acid Obtained from Lab Fermentation. Polish $J$ Chem Technol. 20:81-86.

75. López-Gómez JP, Alexandri M, Schneider R, Latorre-Sánchez M, Coll Lozano C, Venus J (2020) Organic fraction of municipal solid waste for the production of L-lactic acid with high optical purity. $J$ Clean Prod. 247:119165.

76. Ĕgri Ö (2019) Use of microperlite in direct polymerization of lactic acid. Int J Polym Anal Charact. 24:142-149.

77. Coltelli MB, Mallegni N, Rizzo S, Cinelli P, Lazzeri A. (2019) Improved impact properties in poly(lactic acid) (PLA) blends containing cellulose acetate (CA) prepared by reactive extrusion. Materials (Basel). https://doi.org/10.3390/ma12020270.

78. Gupta AP, Kumar V (2007) New emerging trends in synthetic biodegradable polymers - Polylactide: A critique. Eur Polym J. 43:4053-4074.
79. Temur Ergan B, Bayramoğlu M (2018) Poly (l-lactic acid) synthesis using continuous microwave irradiation- simultaneous cooling method. Chem Eng Commun 205:1665-1677.

80. Icart LP, Fernandes E, Agüero L., et al. (2018) End Functionalization by Ring Opening Polymerization: Influence of Reaction Conditions on the Synthesis of End Functionalized Poly(lactic Acid). J Braz Chem Soc 29:99-108.

81. Murariu M, Dubois P (2016) PLA composites: From production to properties. Adv Drug Deliv Rev 107:17-46.

82. Bodros E, Pillin I, Montrelay N, Baley C (2007) Could biopolymers reinforced by randomly scattered flax fibre be used in structural applications? Compos Sci Technol 67:462-470.

83. Siengchin S. (2014) Reinforced flax mat/modified polylactide (PLA) composites: Impact, thermal, and mechanical properties. Mech Compos Mater. 50:257-266.

84. Alimuzzaman S, Gong RH, Akonda M. (2013) Impact Property of PLA/Flax Nonwoven Biocomposite. Conf Pap Mater Sci 2013:1-6.

85. Oksman K, Skrifvars M, Selin JF (2003) Natural fibres as reinforcement in polylactic acid (PLA) composites. Compos Sci Technol. 63:1317-1324.

86. Xia X, Liu W, Zhou L, Hua Z, Liu H, He S (2016) Modification of flax fiber surface and its compatibilization in polylactic acid/flax composites. Iran Polym J (English Ed 25:25-35.

87. Nishino T, Hirao K, Kotera M, Nakamae K, Inagaki H (2003) Kenaf reinforced biodegradable composite. Compos Sci Technol.63:1281-1286

88. Lee BH, Kim HS, Lee S, Kim HJ, Dorgan JR (2009) Bio-composites of kenaf fibers in polylactide: Role of improved interfacial adhesion in the carding process. Compos Sci Technol.69:2573-2579.

89. Glass Fiber Reinforced PLA Bioplastic Compounds Literature.

90. Company R. (2011) GLASS FIBER REINFORCED PLA BIOPLASTIC Sustainable bio-based plastic suitable for durable and semi-durable applications.

91. Wang G, Zhang D, Wan G, Li B, Zhao G. (2019) Glass fiber reinforced PLA composite with enhanced mechanical properties, thermal behavior, and foaming ability. Polymer (Guildf) 181:121803.

92. Ferreira RTL, Amatte IC, Dutra TA, Bürger D. (2017) Experimental characterization and micrography of 3D printed PLA and PLA reinforced with short carbon fibers. Compos Part B Eng. 124:88-100.

93. Li N, Li Y, Liu S. (2016) Rapid prototyping of continuous carbon fiber reinforced polylactic acid composites by 3D printing. J Mater Process Technol. 238:218-225. 
94. Pan Y-J, Lin Z-I, Lou C-W, Huang C-L, Lee M-C, Liao J-M, Lin J-H (2018) Polylactic acid/carbon fiber composites: Effects of polylactic acid-g-maleic anhydride on mechanical properties, thermal behavior, surface compatibility, and electrical characteristics. $J$ Compos Mater. 52:405-416.

95. Kowalczyk M, Piorkowska E, Kulpinski P, Pracella M. (2011) Mechanical and thermal properties of PLA composites with cellulose nanofibers and standard size fibers. Compos Part AAppl Sci Manuf. 42:1509-1514.

96. Sousa S, Costa A, Silva A, Simões R. (2019) Poly (lactic acid)/Cellulose films produced from composite spheres prepared by emulsion-solvent evaporation m e t hod. Polymers ( B a s e l). https://doi.org/10.3390/polym11010066.

97. Csizmadia R, Faludi G, Renner K, Móczó J, Pukánszky B. (2013) PLA/wood biocomposites: Improving composite strength by chemical treatment of the fibers. Compos Part AAppl Sci Manuf. 53:46-53.

98. Wood Filament: The Basics \& Best Brands for Wood PLA|All3DP.

99. Harris AM, Lee EC (2008) Improving mechanical performance of injection molded PLA by controlling crystallinity. J Appl Polym Sci. 107:2246-2255.

100. Lee C, Pang MM, Koay SC, Choo HL, Tshai KY (2020) Talc filled polylactic-acid biobased polymer composites: tensile, thermal and morphological properties. SN Appl Sci 2:1-6.

101. Petchwattana N., Covavisaruch S., Petthai S. (2014) Influence of talc particle size and content on crystallization behavior, mechanical properties and morphology of poly(lactic acid). Polym Bull. 71:1947-1959.

102. Frackowiak S., Ludwiczak J., Leluk K., Orzechowski K., Kozlowski M. (2015) Foamed poly(lactic acid) composites with carbonaceous fillers for electromagnetic shielding. Mater Des. 65:749-756.

103. Guo R, Ren Z, Jia X, Bi H, Yang H, Ji T, Xu M, Cai L (2019). Preparation and characterization of 3D printed PLA-based conductive composites using carbonaceous fillers by masterbatch melting method. Polymers (Basel). https://doi.org/10.3390/polym11101589.

104. Wang G, Zhao G, Wang S, Zhang L, Park CB (2018) Injection-molded microcellular PLA/graphite nanocomposites with dramatically enhanced mechanical and electrical properties for ultra-efficient EMI shielding applications. $J$ Mater Chem $C$. 6:6847-6859.

105. Zhang SM, Liu J, Zhou W, Cheng L, Guo XD (2005) Interfacial fabrication and property of hydroxyapatite/ polylactide resorbable bone fixation composites. Curr Appl Phys. 5:516-518.

106. Li J, X.L. Lu, Zheng YF (2008) Effect of surface modified hydroxyapatite on the tensile property improvement of HA/PLA composite. Appl Surf Sci. 255:494-497.

107. Lämsä T, Jin H, Mikkonen J, Laukkarinen J, Sand J, Nordback I (2006) Biocompatibility of a New Bioabsorbable Radiopaque Stent Material (Ba SO4 Containing Poly-L,D-Lactide) in the Rat Pancreas. Pancreatology. 6:301-305.

108. Yang J, Wang C, Shao K, Ding G, Tao Y, Zhu J (2015) Morphologies, mechanical properties and thermal stability of poly (lactic acid) toughened by precipitated barium sulfate. Russ J Phys Chem . A 89:2092-2096.

109. Abert J, Amella A, Weigelt S, Fischer H (2016) Degradation and swelling issues of poly-(d,l-lactide)/ $\beta$ tricalcium phosphate/calcium carbonate composites for bone replacement. J Mech Behav Biomed Mater. 54:82-92.

110. Schiller C, Rasche C, Wehmöller M, Beckmann F, Eufinger H, Epple M, Weihe S. (2004) Geometrically structured implants for cranial reconstruction made of biodegradable polyesters and calcium phosphate/calcium carbonate. Biomaterials 25:1239-1247.

111. Advantages and Disadvantages of PLA - Bioplastics News.

112. Nofar M, Sacligil D, Carreau PJ, Kamal MR, Heuzey MC (2019) Poly (lactic acid) blends: Processing, properties and applications. Int $\mathrm{J}$ Biol Macromol.125:307-360.

113. Djukić-Vuković A, Mladenović D, Ivanović J, Pejin J, Mojović L (2019) Towards sustainability of lactic acid and poly-lactic acid polymers production. Renew Sustain Energy Rev. 108:238-252.

114. Polylactic Acid (PLA) Production. 